\title{
Mobilidade urbana e acidentes com motofretistas: questão social, política pública e trabalho
}

Eric Teixeira Gaigher ${ }^{1}$

Gissele Carraro²

Silvia Moreira Trugilho ${ }^{3}$

Maria Carlota de Rezende Coelho ${ }^{4}$

\begin{abstract}
Resumo
O artigo aborda a mobilidade urbana e os acidentes de trânsito envolvendo trabaIhadores motofretistas, dialogando com a categoria "Questão Social" no bojo do capitalismo contemporâneo. Produzido a partir de uma pesquisa que teve como fonte os dados de acidentes motociclísticos do período de 2012 a 2017, do banco dados do Departamento de Informática do Sistema Único de Saúde, traz uma reflexão sobre a precarização do trabalho dos motofretistas e as condições desiguais de mobilidade urbana na realidade brasileira. Conclui-se que as condições de trabalho e vida dos motofretistas se inserem no debate atual da "Questão Social", decorrente do reordenamento do capital em seu processo de expansão e seu sistema exploratório dominante.
\end{abstract}

\section{Palavras-chave}

Mobilidade Urbana. Questão social. Acidentes motociclísticos. Trabalho. Políticas Públicas.

Urban mobility and motorcyclist accidents: social issue, public policy and work

\begin{abstract}
Urban mobility and traffic accidents involving motofretista workers are discussed, dialoguing with the category "Social Issue" in the midst of contemporary capitalism. The text is the result of a study with a qualitative approach that used data from motorcycle accidents from 2012 to 2017 as sources, available in the database of the Department of Informatics of the Unified Health System and the relevant literature. The accident data and the scientific literature consulted allowed to apprehend and critically reflect on the precarious work of motofretistas and the unequal conditions of urban mobility in the Brazilian reality. It is concluded that the working and living conditions of motofretistas, currently called "service proletariat" fits the current discussions of the "Social Issue", resulting from the rearrangement of capital in its expansion process and its dominant exploratory system.
\end{abstract}

Keywords

Urban Mobility. Social Issue. Motorcycle accidents. Work. Public Policies. 
Artigo recebido em março de 2021

Artigo aprovado em agosto de 2021

\section{Introdução}

Trabalhadores que se utilizam da motocicleta como ferramenta de trabalho se inserem nas categorias de mototaxistas e motofretistas. No primeiro grupo situam-se aqueles que se utilizam da motocicleta para atuarem informalmente no transporte individual de passageiros, o que pode ser verificado em algumas cidades brasileiras (ALMEIDA, MEDEIROS PINTO, et al. 2016). Já no segundo grupo estão inseridos os trabalhadores que realizam transporte remunerado de mercadorias por meio da motocicleta (motofrete), antes denominados de motoboys, sendo uma categoria profissional que agrega um número maior de trabalhadores em relação à primeira, atuando de forma mais ativa nos grandes centros urbanos (FRACA, 2016). Este texto abrange o segundo grupo na relação com a mobilidade urbana e os acidentes de trânsito no curso de sua atividade laborativa e utiliza a categoria "Questão Social", no contexto do capitalismo contemporâneo, apontando os seus desdobramentos sobre a flexibilização das relações de trabalho e a precarização do trabalho desse crescente segmento da classe trabalhadora.

Os motofretistas na atualidade se inserem no "novo proletariado de serviços na era digital" (ANTUNES, 2019, p. 34). É um novo tipo de trabalhador que está diretamente vinculado às tecnologias da informalidade na era digital e, submetido a um processo de exploração extremo. Diferente da classe operária clássica do século XX, o seu trabalho não é material, mas é proletário, denominado pelo autor como o "proletariado de serviços", que vive uma realidade que oscila entre o desemprego completo e a disponibilidade para tentar obter o "privilégio da servidão". 
Além das altas taxas de mortalidade e sequelas oriundas dos acidentes, os motofretistas se inserem em um mundo do trabalho mais heterogêneo e fragmentado, tanto no que se refere ao tipo de trabalho, quanto na composição da classe trabalhadora reunificada na atualidade, pela condição de assalariamento e marcada pela "devastação neoliberal do trabalho" (ANTUNES, 2018, p. 45), expressa na precarização, na informalidade, na terceirização e no desemprego estrutural (ANTUNES, 2018).

As vias públicas das grandes cidades brasileiras constituem-se o ambiente de trabalho desse segmento da classe trabalhadora, caracterizando-se como espaços de maior vulnerabilidade a acidentes, tanto pela exposição quanto pela necessidade de realizarem o maior número possível de entregas em curto intervalo de tempo num trânsito caótico - característica atual que configura o padrão de mobilidade urbana dos grandes centros urbanos.

As condições e configurações atuais de deslocamento de pessoas e bens nos espaços geográficos dos centros urbanos - que constituem a denominada mobilidade urbana -, especialmente nas regiões metropolitanas brasileiras, revelam uma realidade de contundente inequidade nas formas de locomoção de pessoas das diferentes classes sociais. Para Trindade (2012), essa realidade afeta sobremaneira a população de baixa renda dependente exclusivamente do transporte coletivo, em grande medida estruturado sem planejamento para atender as populações que foram segregadas das áreas de melhor localização e valor econômico em função da dinâmica de ocupação socioespacial das grandes cidades; dinâmica essa que resulta em espaços de intenso crescimento das periferias pobres contrapondo-se às áreas de crescimento das classes dominantes (DA CUNHA CALADO; FURTADO; DIAS et al., 2018).

A análise de Harvey (1989) aponta a relação entre os espaços geográficos e o movimento do capital em seus interesses acumulativos e movimento expansionista, permitindo-nos compreender como sua 
dinâmica e movimento comportam intenções econômicas seletivas relacionadas às classes sociais, criando uma divisão desigual de acesso e usufruto de bens e serviços da sociedade, na medida em que produz espaços submetidos aos interesses dominantes do capital.

A população residente nas periferias das grandes cidades, sem acesso ou com acesso insuficiente aos meios de transporte e tendo necessidade de locomoção para o trabalho, busca alternativas de locomoção por meio de bicicleta, a pé, ou motocicletas, existindo, portanto, uma relação direta entre mobilidade, transporte e trabalho. As oportunidades de trabalho formal ou mesmo de trabalho informal, para as populações segregadas, são mais atrativas nos espaços das cidades ocupados pelas classes dominantes. Dessa forma, por ser considerada mais flexível no trânsito em função da possibilidade de trafegar entre os demais veículos, de custo mais acessível que o carro, a moto se tornou um importante ativo no enfrentamento à situação de desemprego, pois viabilizou, principalmente aos jovens, o acesso a oportunidades de emprego em lugares distantes de suas residências, além de servir como ferramenta de trabalho em vagas informais (SILVA, 2011).

Segundo o Departamento Nacional de Trânsito (DENATRAN), citado no Boletim Estatístico da Seguradora Líder - DPVAT de 2017, a frota de motocicletas no Brasil em 2017 era de 25,7 milhões, correspondendo a $27,26 \%$ da frota nacional. Numa análise sobre as tendências nacionais de acidentes de trânsito nas últimas décadas no país, Cruz (2019) assinala que estes indicam uma evolução diferente do resto do mundo, com reduções expressivas na mortalidade de pedestres; ligeiro aumento da mortalidade de ocupantes de automóveis e acentuado aumento na letalidade de motociclistas.

Verifica-se que a mortalidade por acidentes com motocicletas se mostra uma realidade contundente nas grandes cidades brasileiras, apesar da subnotificação das causas dos óbitos no sistema de mortalidade (SIM) no Brasil. Os números ainda assim são alarmantes. Em 2017 ocorreram 10.101 óbitos entre jovens e adultos na faixa etária de 15 a 49 
anos de idade (DATASUS, 2019). Esses dados de realidade revelam ser os motofretistas trabalhadores vulneráveis a acidentes de trânsito sujeitos a perder a vida precocemente em função do deslocamento no trânsito em cumprimento às atividades de trabalho, ou mesmo para suprir suas necessidades relativas à bens e serviços (VASCONCELLOS, 2016).

A ocupação socioespacial das cidades caracterizada pela divisão da sociedade em diferentes classes sociais revela que grande parte dos moradores das áreas de periferia é composta por desempregados, subempregados, trabalhadores informais, pertencentes às classes subalternas que sem o devido acesso aos meios de transporte se utilizam das motocicletas, como meio de locomoção. E, sendo a moto um transporte vulnerável, as desiguais oportunidades de acesso ao transporte, ao trabalho e às condições sociais de vida de grande parte das pessoas pertencentes à classe trabalhadora nos levam a considerar a categoria "Questão Social" como referência para a reflexão e debate a respeito da mobilidade urbana e os acidentes motociclísticos relacionados aos trabalhadores motofretistas.

Essa afirmativa se ancora no entendimento de que a questão social em seu aspecto dinâmico vem assumindo atualmente novas manifestações que revelam necessidades sociais de grande parcela da população brasileira, aí incluídos os trabalhadores motofretistas, as lutas dos trabalhadores pelo reconhecimento de seus direitos e as refrações nas políticas públicas, que sofrem a influência direta do avanço do neoliberalismo no estágio atual de desenvolvimento do capitalismo, que vem de forma vertiginosa favorecendo o capital em detrimento do trabalho (IAMAMOTO, 2013).

O contexto social atual encontra-se profundamente afetado pelo novo padrão de acumulação capitalista mundializado e financeirizado, seu reordenamento produtivo e a adoção do ideário neoliberal na condução das políticas econômicas e sociais, resultando na intensifıcação do conjunto das expressões das desigualdades sociais geradas pelas necessidades capitalistas (NETTO, 2012), que se traduzem em múltiplas formas de manifestação da questão social contemporânea. 
No que diz respeito às classes trabalhadoras, a precarização do trabalho, a redução dos níveis de emprego, a regressão das políticas sociais públicas de proteção social - aspectos resultantes do atual padrão de acumulação capitalista -, incidem de modo nefasto sobre as condições objetivas de vida do conjunto dos trabalhadores. Ademais, o espaço urbano se constitui, movimenta e se transforma a partir da correlação de forças e disputas de interesses inseridas no processo de reprodução ampliada do capital cujos resultados, segundo Pereira (2010), se expressam na forma de concentração dos meios de produção, aumento de desigualdades e inequidade na fruição de bens e serviços.

Nessa realidade atual vimos intensificar a questão social, como produto da exploração e dominação capitalista implícitas nas condições e relações de trabalho, apropriação de riqueza, transformações sociais, políticas e econômicas. Por quanto expressa o conjunto de desigualdades na sociedade capitalista, a questão social se manifesta nas formas de precarização da vida social e do trabalho decorrentes do modo de produção e acumulação capitalista e se redimensiona e se radicaliza, como resultado do movimento histórico expansionista do capital no cenário mundial (IAMAMOTO, 2008). Nesse aspecto, a mobilidade urbana, como fator que incide sobre a condição de trabalho e mortalidade de trabalhadores motofretistas, se revela, assim, como uma expressão contemporânea da questão social.

Partindo do pressuposto de que a mobilidade urbana e os acidentes motociclísticos podem ser analisados a partir do conceito da questão social, busca-se desenvolver uma análise crítica e reflexiva sobre mobilidade urbana e os acidentes motociclísticos, com especial atenção para os que envolvem trabalhadores motofretistas.

A produção de conhecimento que ora se apresenta resulta de pesquisa social aplicada, de abordagem qualitativa, que teve como fontes: a) os dados de mortalidade por acidentes de moto no período de 2012 a 2017 disponíveis no banco de dados do Departamento de Informática do Sistema Único de Saúde (DATASUS) b) a literatura científıca 
pertinente ao objeto de estudo, localizada prioritariamente nas bases de dados indexadas na área da saúde e ciências sociais aplicadas.

Os dados de mortalidade envolvendo óbitos por causas externas, aí incluídos os acidentes com motociclistas no Brasil são extraídos do DATASUS, utilizando o Código Internacional de Doenças (CID10), correlacionado às variáveis: munícipio; faixa etária; escolaridade; sexo; raça/cor; estado civil; e local da ocorrência, desde que o preenchimento das Declarações de Óbitos (DO) tragam estas informações.

Os CIDs relacionados aos acidentes envolvendo motociclistas foram categorizados de V2O a V29, que especificam os diferentes obstáculos de colisão da motocicleta, correlacionados às variáveis. Portanto, a confiabilidade e completude das informações para gerar o banco de dados do DATASUS, que envolvem os acidentes com motocicletas estão diretamente ligadas ao correto preenchimento das Declarações de Óbitos no território brasileiro.

É importante aqui destacar que a subnotificação das informações em saúde no Brasil é um fato histórico. Tentando minimizar tal fato, principalmente a mortalidade por causas externas - que em grande parte era computada como causa indeterminada - em 2011, o Ministério da Saúde promoveu uma mudança no conteúdo da Declaração de Óbito, cujo objetivo foi o detalhamento das informações a serem coletadas (BRASIL, 2011). Dessa forma, acredita-se que os dados a partir de 2012 sejam mais fidedignos. Por esta razão, tomou-se como referência para as reflexões contidas neste texto os dados registrados no DATASUS a partir de 2012, tendo como período de corte o ano de 2017.

A mudança no estado de transição urbana (da concentração de população em área rural para espaços urbanos), do status social das motocicletas (de objeto de fetiche a ferramenta de trabalho) associados à transição epidemiológica (que revela modificações no padrão de morbidade e mortalidade para situações de agravo de saúde por causas externas) tem como uma de suas características e elemento de preocupação, os acidentes de trânsito envolvendo motociclistas. Esse tipo 
de acidente apresenta maior risco ao ser comparado a outros meios de transporte, pelo expressivo número de adultos jovens envolvidos e pela condição social vulnerável, além dos elevados custos para o Estado, para as famílias e os danos sociais inerentes.

\section{Urbanização, mobilidade urbana e os acidentes motociclísticos}

As condições de vida estão associadas a uma variedade de fatores, sendo o modo de produção capitalista e a dinâmica das relações de trabalho o ponto primordial. A partir de tal fato, é possível fazer uma leitura dessas condições por meio de uma análise da expansão da urbanização, com seus serviços, infraestrutura, espaços, relações sociais e níveis de consumo, aspectos relacionados diretamente ao processo de acumulação do capital (KOWARICK, 1979; 2016). Entende-se por urbanização como a concentração espacial de uma população, a partir de certos limites de dimensão e de densidade; essa, por conseguinte comporta uma difusão do sistema de valores, atitudes e comportamentos denominado 'cultura urbana' (CASTELLS, 2009; 2018).

A constituição de espaços urbanos no Brasil segue um padrão de subordinação do país na divisão internacional do trabalho, resultando em dinâmicas de formação socioespacial e divisão socioterritorial do trabalho, subordinadas a projetos externos (PEREIRA, 2010). Tal subordinação comporta importantes consequências, na medida em que gera significativas desigualdades sociais, considerando, ainda o processo de desenvolvimento econômico brasileiro em um padrão de capitalismo periférico e dependente.

No Brasil, a industrialização iniciada por volta da década de 1930 e intensificada a partir dos anos de 1950, centrada na produção de insumos para a indústria, favoreceu o crescimento da urbanização em meio a organização da indústria nacional com exportação de produtos manufaturados e matérias-primas para atendimento aos interesses do grande capital internacional. Como efeitos deletérios desse processo podemos citar o crescimento desordenado dos centros urbanos, 
a concentração de riqueza e acentuação das desigualdades sociais, a produção de espaços segregados e de formas precarizadas de vida humana nas periferias das grandes cidades - aspectos marcantes de manifestação da questão social brasileira.

O processo de formação das áreas urbanas no Brasil resultou em grandes cidades brasileiras que apresentam aspectos físico-espaciais com aparência desordenada do crescimento metropolitano, o que é evidenciado pelo traçado irregular com desconexos espaços vazios e ocupados que revelam formas díspares de ocupação do espaço urbano. A distribuição espacial da população no quadro desse caótico crescimento da urbanização reflete a condição social dos habitantes da cidade (KOWARICK, 1979; 2016).

Destaca-se ainda que a constituição, manutenção e transformação do espaço urbano se dá em meio a um processo de correlação de forças e disputas de interesses entre os diversos atores que o ocupam (NASCIMENTO 2016). Neste aspecto, o urbano se converte em espaço de reprodução do capital e das classes sociais, em meio à luta de classes que compõem o modo de produção capitalista (MANCINI, 2008).

O modelo de urbanização adotado no Brasil acentua a distância entre o centro e a periferia ${ }^{5}$ das grandes cidades, concomitante às desigualdades existentes entre as populações que habitam esses distintos espaços, no que diz respeito tanto às condições de vida como ao usufruto dos bens e serviços existentes na sociedade. Em relação às condições de mobilidade urbana, por exemplo, verifica-se comumente entre os trabalhadores residentes nas áreas periféricas dos grandes centros urbanos problemas de deslocamento da moradia para o trabalho, dificuldade de acesso ao transporte coletivo e a má qualidade do mesmo. Kowarick (1979; 2016) refere que o agravamento dos problemas que afetam a cidade incide diretamente na qualidade de vida da população, principalmente no surgimento e expansão dos bairros periféricos que alojam a população trabalhadora, concentram a pobreza da cidade e de seus habitantes. Neste aspecto 
denota a exclusão social de amplas parcelas da população, como uma manifestação da questão social brasileira.

O vertiginoso crescimento demográfico urbano, levou ao amontoamento de populações em áreas longínquas, afastadas do local de trabalho, impondo-se distâncias de deslocamento cada vez maiores (KOWARICK, 1979; 2016). No âmbito da mobilidade urbana, observa-se atualmente em economias como a brasileira que na circulação de pessoas pelos espaços urbanos há, em média, dois deslocamentos diários (PONTES; MACIEL, 2017). Tais deslocamentos são realizados em maior ou menor nível de conforto, conforme as condições de cada usuário. Condição essa que implica maior consumo de tempo, espaço, energia, recursos financeiros e geração de externalidades negativas, como poluição do ar, acidentes de trânsito e os tão problemáticos congestionamentos (PONTES; MACIEL, 2017; PERO; STEFANELLI, 2015).

A média de congestionamentos nos grandes centros urbanos, conforme afirmam Pontes e Maciel (2017), vem aumentando significativamente e poucas são as pessoas que sabem lidar com essa realidade. Estudos apontam, ainda, que esse crescimento de congestionamento gera não só um aumento considerável no custo das viagens, ou de combustível, mas também aumentam o número de colisões decorrentes de um fluxo intenso frequente.

Faz-se importante acrescentar, partindo do contexto histórico, que no Brasil há uma preferência pelo transporte rodoviário que, desde 1960, vem apresentando um crescimento intenso motivado pelo aumento imperativo da urbanização (PONTES; MACIEL, 2017). Diante da intensificação da urbanização no Brasil, o sistema de mobilidade do país passou a apresentar baixa qualidade e alto custo, regado a impactos negativos à vida de seus usuários e nos custos econômicos e ambientais para a sociedade (PONTES; MACIEL, 2017).

A partir desse contexto, as efetivas condições de mobilidade urbana passaram a ser fundamentais, pois por meio delas torna-se possível avaliar a qualidade de vida urbana no país e identificar ações 
políticas que almejam melhorias e o aumento da eficiência na movimentação de pessoas, bens e serviços dentro dos centros urbanos (PONTES; MACIEL, 2017).

O tempo de deslocamento de casa para o trabalho depende da distância, do meio de transporte utilizado e do congestionamento, apresentando assim uma sensível relação com a dinâmica de oportunidades de emprego e de moradia das várias metrópoles na sua conformação. Já os custos dependem da qualidade do transporte público. Neste sentido, as questões inerentes à mobilidade urbana nas grandes cidades apontam para a necessária formulação de políticas públicas que visem à melhoria das condições urbanas de mobilidade para a população, ou seja, as que reduzam o tempo de deslocamento e/ou seus custos, diante das configurações espaciais e socioeconômicas de cada região (PERO; STEFANELLI, 2015).

A Política Nacional de Mobilidade Urbana (PNMU), instituída pela Lei n. ${ }^{\circ} 12.587 / 12$, é um importante marco legal na gestão de políticas públicas urbanas, revestido do propósito de contribuir para o desenvolvimento urbano e o acesso universal à cidade. A PNMU define as diretrizes que devem orientar a regulamentação e o planejamento da mobilidade urbana nas cidades do país.

Essa política pública se destaca com o mérito de obrigar os gestores das cidades a priorizarem e incentivarem os modais; na perceptiva de corrigir a distorção cultural do planejamento dos deslocamentos que ocorrem no Brasil. A PNMU também assinala que os municípios com mais de 20 mil habitantes, que correspondem a 30\% das cidades do País, têm a responsabilidade de elaborar um Plano de Mobilidade Urbana (PMU) para abarcar as diretrizes da lei e traçar juntamente com a sociedade civil um planejamento de curto, médio e longo prazo, para regulamentar como ocorrerão os deslocamentos de bens e pessoas na cidade (RUBIM; LEITÃO, 2013). O PMU deve visar o crescimento ordenado das cidades e a Política Nacional de Mobilidade Urbana determina que os planos priorizem os transportes públicos e aqueles 
não motorizados, bem como o planejamento da infraestrutura para os deslocamentos a pé ou por bicicleta.

Para maior efetividade de um PMU faz-se necessário uma eficaz gestão do trânsito, o que consequentemente irá melhorar as condições de mobilidade e a qualidade de vida dos habitantes (PONTES; MACIEL, 2017).

O legislador deve priorizar o PMU partindo do princípio que a questão da segurança assume relevância ante os elevados índices de mortes decorrentes de acidentes no trânsito. Esses acidentes representam um impacto na sociedade e na saúde, pois o risco de traumas e internação das vítimas constituem um indicador da gravidade dos acidentes. A moto se destaca dentre os principais transportes envolvidos nos índices de morte no trânsito, tendo em vista que o uso de motos como instrumento de trabalho vem crescendo em proporções alarmantes e seus problemas se tornaram mundial (BARROS; SILVA; ROSENO et al., 2018). O trânsito envolvendo motocicletas abarca uma complexidade de fatores sociais, econômicos e culturais, que determinam a sua insegurança.

A cidade se transforma em razão de processos globais relativamente contínuos e em função de profundas modificações no modo de produção, nas relações de classe e de propriedade (CUNHA, 2008). $\mathrm{Na}$ busca por melhores condições de vida e salário, novos tipos de trabalho surgem no Brasil, e essa tendência vem modificando os hábitos da população. No que se refere aos motociclistas, é curioso ressaltar que até o final da década de 1980, a motocicleta era considerada artigo de luxo e/ou para práticas esportivas, sendo limitada a um seleto grupo de pessoas da elite ou da classe média.

Nas últimas décadas observa-se um crescimento na quantidade de motocicletas nas ruas, com seu uso associado ao instrumento de trabalho, lazer e satisfação das necessidades sociais contemporâneas. A motocicleta é um modo de transporte urbano mais barato, acessível a praticamente todas as camadas sociais (RODRICUES; ARMOND; COLOMBO-SOUZA et al., 2014), em comparação a outros veículos motores, para o trânsito ágil nas grandes cidades, além do acesso ser 
viabilizado pelo sistema de financiamento de crédito. Na função de instrumento de trabalho, a motocicleta se insere nas atividades de mototáxi, para transporte de passageiros e de motofretista, para a prestação de pequenos serviços de entrega - o motofrete (ALMEIDA; MEDEIROS; PINTO et al., 2016). Na maioria dos casos, no entanto, é utilizada para exercer atividades laborais informais, que vêm se expandindo com o fenômeno da uberização dos motofretistas, em atendimento à sociedade de consumo contemporânea.

Ante a essa realidade, as vendas internas de motocicletas no Brasil passaram a crescer exponencialmente de 123 mil unidades, em 1990, para quase 1 milhão, em 2004. O baixo custo da motocicleta, tanto na aquisição quanto na manutenção, as facilidades de estacionamento, a rapidez e a facilidade de circulação têm levado à sua grande procura. Não obstante, isso tem incidido num grande aumento do índice de acidentes que envolvem motociclistas.

Dimensões socioeconômicas importantíssimas também foram responsáveis por tal evolução. No tocante ao ciclo completo dessa mercadoria (Dinheiro-Mercadoria/Produção-Dinheiro), atuaram em todas as etapas. No primeiro momento desse, iniciativas estatais de subsídio à produção e expansão do setor em conjunto com crédito nacional (CARVALHO, 2016) e internacional facilitados diante de um processo de abertura e desnacionalização com grande "liquidez internacional". Do ponto de vista da produção, aumento forte do número de ocupados no setor automotivo (de cerca de 3,5 milhões a em torno a 6,5 milhões de trabalhadores entre 1998 e 2014), pela grande disponibilidade de força de trabalho com a qualificação necessária gerada por anos de crise e neoliberalismo. Esse setor, um dos mais organizados da classe trabalhadora brasileira, apresenta níveis e dinâmica da taxa de mais-valia relativamente contidos (FRANKLIN et al, 2021). Por fim do ponto de vista da compra final, o aumento da renda da maioria dos brasileiros, em conjunto com políticas de crédito subsidiado ao consumo ou redução 
de impostos para veículos abaixo de 1.000 cilindradas, permitia o fechamento crescente do ciclo (CARVALHO, 2016).

Historicamente, o século XX foi marcado pelo desenvolvimento da indústria automotiva o que proporcionou um considerável aumento na frota de veículos no mundo. Após a Segunda Grande Guerra Mundial, o automóvel passou a ser considerado objeto de consumo e de status social, apoiado principalmente pela mídia/propaganda nas sociedades capitalistas (MESQUITA FILHO, 2012).

Consequentemente, a partir dos anos 1960, os acidentes de trânsito e os agravos à saúde associados à violência, como os homicídios, passaram a se destacar como um problema de grande relevância em saúde pública no Brasil, por serem considerados causas externas de morbimortalidade que apresentam significativa magnitude e impacto na vida das pessoas (MESQUITA FILHO, 2012; MORAIS NETO; MALTA; MASCARENHAS et al., 2010).

Na década de 1980 observou-se um aumento da taxa de mortalidade por causas externas, tendo os acidentes de trânsito como os maiores responsáveis por um expressivo número de mortes, hospitalizações e lesões temporárias ou permanentes, tendo em vista que se considera o trânsito no Brasil um dos mais perigosos do mundo (CORCOZINHO; MONTAGNER, 2017; ALMEIDA; MEDEIROS; PINTO et al., 2016).

Em fins do século $X X$, entre os acidentes de trânsito, observou-se um aumento expressivo de acidentes envolvendo motocicletas. Independentemente da região ou do tamanho do município, a moto tornou-se, cada vez mais, um tipo de veículo bem aceito e aprovado pela população, por ser mais ágil, com custo de manutenção reduzido, facilidade de aquisição e facilidade de deslocamento nos congestionamentos (COLIAS; CAETANO, 2013).

Segundo Botelho e Gonzaga (2017) o crescimento da frota de motocicletas no Brasil foi de 101, 9\% no período compreendido entre janeiro de 2008 a dezembro de 2014, mês que apresentava 19.242.916 motocicletas circulando no país, correspondendo a $22,9 \%$ da frota total de veículos. 
Em consequência, dados da Organização Mundial de Saúde (OMS) relevam que no mundo o número de pessoas que morrem por ano em decorrência dos acidentes de trânsito é estimado em 1,2 milhão, o que representa aproximadamente $12 \%$ dos óbitos (MORAIS NETO; MALTA; MASCARENHAS et al., 2010). Anualmente são 1,3 milhões de mortes entre 20 e 50 milhões de pessoas lesionadas, essa tendência é crescente nos países de média e baixa renda (MALTA; ANDRADE; COMES et al., 2016; MORAIS NETO; MONTENEGRO; MONTEIRO et al., 2012).

Em 2019 - últimos dados disponíveis no DATASUS - foram registrados 11.182 óbitos por acidentes envolvendo motocicletas, desses $71,37 \%$ corresponderam a óbitos na faixa etária de 20 a 49 anos. Estimativas apontam uma crescente tendência desse percentual que tende a aumentar em $40 \%$ até 2030, caso não sejam implementadas medidas preventivas (MORAIS NETO; MALTA; MASCARENHAS et al., 2010).

A maior probabilidade de acidentes de trânsito envolvendo motocicletas está relacionada à vulnerabilidade dos motociclistas, e o risco de morte chega a ser até vinte vezes maior em comparação aos condutores de automóveis (CORGOZINHO; MONTAGNER, 2017). O risco é elevado entre os indivíduos na faixa etária de 15 a 39 anos; com o agravante de que nessa faixa etária, os acidentes de motocicleta perfilam entre as causas principais de morte, perfazendo um percentual de 37,8\% e 40,1\% dos casos, respectivamente (NORONHA; MORAIS, 2011).

Botelho e Gonzaga (2017) ressalvam que a mortalidade por acidente motociclístico é um sério problema de saúde pública e tão relevante quanto à problemática causada aos feridos por esses acidentes. Os acidentes determinam uma gama de prejuízos individuais e para a sociedade, decorrentes das sequelas temporárias ou permanentes, invalidez, perda de dias de trabalho, elevados custos para os serviços de saúde e gastos com indenizações.

O grande crescimento de vendas de motos em detrimento ao proporcional aumento do transporte público coletivo para atendimento do capital fez com que esse veículo, de fácil acesso e manutenção, se 
tornasse não apenas uma das principais formas de locomoção e de trabalho agravada frente ao fenômeno da uberização da moto e das tecnologias da informalidade na era digital (ANTUNES, 2019).

A migração populacional do meio rural para o urbano ocorrida especialmente na segunda metade do século $X X$, estimulada pela política desenvolvimentista centrada no processo de industrialização e modernização do País, constitui-se expressão da questão social no Brasil, inerente ao processo de constituição do capitalismo brasileiro. Nesse processo, a intensificação da migração do espaço rural para o urbano, assentada na dinâmica e movimento do capital para atendimento de seus interesses acumulativos, acarretou e ainda vem acarretando o desenvolvimento da maioria de cidades sem a justa adequação no aproveitamento e na ocupação territorial, produzindo, por consequência, espaços geográficos contraditórios na concentração de poder político e econômico, além de uma divisão desigual de acesso e usufruto de bens e serviços da sociedade.

Os fluxos migratórios de trabalhadores em busca de oportunidade de trabalho acompanham, ou melhor, são estimulados e determinados pelo movimento das atividades produtivas da economia brasileira, subordinada ao mercado externo, podendo ser verificados tanto em épocas passadas, como no contexto atual. Além de manifestação da questão social no Brasil, reafirmam processos de trabalho precarizado, maximização de lucro e constituição de territórios de periferia urbana, onde habitam os especialmente os trabalhadores destituídos dos meios de produção.

A ausência de adequação no aproveitamento e na ocupação territorial contribui para a periferização da população urbana, que significa a criação de áreas habitacionais distantes dos centros urbanos. Com isso, configura-se o desequilíbrio espacial, pois não são todos os casos em que a oferta de emprego, educação, saúde, lazer e serviço está próxima à moradia das pessoas. Logo, o modo da população se deslocar é impactado, passando a ser mais longo, dispendioso e ineficiente (NTU, 2017). 
O Brasil atualmente se encontra em um avançado processo de urbanização que, firmado no desenvolvimento desordenado das cidades, resultou em antagonismos de ocupação social dos espaços urbanos pela população e sérios problemas relacionados à mobilidade urbana. Paralelo a isso, com vistas ao atendimento dos interesses acumulativos da indústria automobilística, vimos ocorrer a expansão da frota de veículos, facilitada pela maior oferta de crédito e pela política de incentivos adotada pelo governo desde os anos 1930 (PERO; STEFANELLI, 2015; RUBIM; LEITÃO, 2013). Verifica-se com isso que mais de 50\% dos domicílios já possuem um automóvel ou uma moto (PERO; STEFANELLI, 2015).

O país apresentou uma significativa expansão de frotas de automóveis e utilitários entre 2000 e 2016, com um aumento de 160,4\%, passando de 20 milhões para mais de 52 milhões de veículos; a frota de motocicletas e motonetas de 2000 a 2016 aumentou em 520\%. Em 2000, circulavam no país aproximadamente 3,9 milhões de motocicletas e motonetas, em 2016, esse quantitativo passou para aproximadamente 24,9 milhões (NTU, 2017). O resultado dessa expansão está na deterioração das condições de mobilidade urbana, na qual se verifica o aumento de óbitos entre os trabalhadores motofretistas.

\section{Vulnerabilidade do trabalho do motofretista}

Como já apontado, o uso da motocicleta como meio de transporte vem crescendo de modo significativo no país, fato esse que vem ocasionando maior exposição do usuário nas vias públicas e consequentemente maior probabilidade de acidentes e mortalidade (RODRIGUES et al., 2014; MARTINS; BOING; PERES, 2013; SCHOELLER; BONETTI; SILVA et al., 2011). Atualmente, o aumento na quantidade de trabalhadores motofretistas circulando no trânsito sugere que eles desempenham tarefas que satisfazem as necessidades sociais do setor de serviços. A intensidade desse fluxo de circulação levanta questões relevantes, como a necessidade de implantação de políticas públicas 
sociais de monitoramento e prevenção de acidentes motociclísticos, uma vez que a prevenção de acidentes é o meio mais eficaz para redução da morbimortalidade por causas externas (RODRICUES; ARMOND; COLOMBO-SOOUZA et al., 2014).

Pode-se explicar o aumento do uso de motocicletas como instrumento de trabalho pelo desemprego entre jovens na última década. No setor de serviços a profissão de motofretista representa uma das que vem exibindo um crescimento exacerbado de trabaIhadores que utilizam as motos como ferramenta de trabalho. Essa tendência tem sido facilitada, porque, a motocicleta é um veículo que ganha cada vez mais aceitação e aprovação da sociedade, por ser mais ágil e custo baixo. Com isso, na última década, dentre os acidentes de trânsito, observa-se um significativo aumento no número de acidentes envolvendo trabalhadores motofretistas, segundo dados identificados pelas instituições de trânsito, transporte e saúde (SANTANA; ANDRADE; CARDIM, 2015)

Os motofretistas são mais susceptíveis e/ou vulneráveis a sofrerem acidentes, pela maior exposição nas vias públicas e pela necessidade de realizarem o maior número possível de entregas em um curto intervalo de tempo, levando-os à adoção de altas velocidades e de arriscadas manobras no trânsito. Os indicadores de mortalidade por acidentes motociclísticos são revelados pela literatura como condições que crescem em uma proporção superior ao crescimento populacional (SCHOELLER; BONETTI; SILVA et al., 2011), sendo mais expressiva essa condição em países de baixa e média renda (MARTINS; BOING; PERES, 2013).

Os estudos de Botelho e Gonzaga (2017) e Abreu et al. (2012) revelaram que a mortalidade é um sério problema de saúde pública e não menos importante são os problemas gerados naqueles acometidos pelo acidente motociclístico, principalmente a família que além do sofrimento pela perda do ente querido tem redução na renda familiar. Além disso, esses mesmos autores fazem alusão a um estudo desen- 
volvido pelo Instituto de Pesquisa Econômica Aplicada (IPEA) que estimou que um acidente fatal em rodovia federal gera para a sociedade um custo de mais de $\mathrm{R} \$ 600.000,00$.

As exigências de pontualidade, confiabilidade, presteza, principalmente na era da informalidade digital - como exemplo o aplicativo ifood - são os indicadores principais para esses trabalhadores adotarem comportamentos de riscos no trânsito. Aliada à pressão por entregas rápidas, aparece a remuneração por produtividade como fator responsável pela adoção de práticas nem sempre seguras na entrega de mercadorias. Embora a velocidade não seja um registro da profissão é, todavia, observada nas ruas e nas falas dos próprios motofretistas, que veem na velocidade de entrega, o sentido do seu trabalho. Vale destacar o aumento da subordinação do trabalhador nessa relação de trabalho, que gera escolhas determinadas socialmente. A forma como a força de trabalho vem sendo explorada tem levado a condições extremas de ameaça à vida.

Com a elevada participação dos motofretistas em acidentes de trânsito, o tema passou a ser preocupação em âmbito mundial. No Brasil, em 2009, a Classificação Brasileira de Ocupações (CBO), a Lei $n^{\circ}$. 12.009/09, regulamentou o exercício dos profissionais de transporte em motocicletas, na entrega de mercadorias e serviços passando a denominá-los de motofretista (SANTANA; ANDRADE; CARDIM, 2015). Mas, essa condição não diminuiu o número de acidentes envolvendo motocicletas, ao contrário, aumentou de modo alarmante.

A Organização Internacional do Trabalho (OIT) apresentou a terminologia vulnerabilidade social do trabalhador, no sentido de um estado de elevada exposição a determinados riscos ou incertezas, associado à uma capacidade reduzida para se proteger ou defender-se deles, em que o trabalhador se encontra fragilizado para fazer frente as consequências negativas (LIMA; PACHÚ, 2016).

O tema da fragilidade humana se dá a partir de contextos dos agravos e violências, tendo como exemplo, os motofretistas, que 
são profissionais vulneráveis a acidentes de trânsito. A utilização da motocicleta como ferramenta de trabalho vem contribuindo para o crescimento de incidentes e constituindo-se em acidentes de trabalho (SANTANA; ANDRADE; CARDIM, 2010). No trânsito, em meio às diferentes condições de mobilidade urbana, grupos sociais mais suscetíveis a acidentes e vulneráveis ao risco de lesões, como o caso do motofretista, é intensificado pelas condições de precariedade do trabalho (BOTELHO; GONZACA, 2017).

Dentro dessas condições precárias de trabalho inscrevem-se elementos como: “[...] ausência de contratos formais de trabalho, negação de direitos trabalhistas, condições adversas no cotidiano de serviço, jornadas extensas e alternâncias de turnos, gerando estresse e cansaço físico [...]" (BOTELHO; CONZACA, 2017, p. 12). A vulnerabilidade social do trabalho supera o caráter individual do conceito de insegurança e risco, e surge como um conjunto coletivo que leva à susceptibilidade de agravos à saúde e à vida. Os efeitos prejudiciais atrelados à pobreza socioeconômica caracterizam as situações de violência como também se agravam pela desigualdade relacionada ao sexo, etnia, raça, região geográfica e intergrupos, como o trabalho dos motofretistas (CORCOZINHO; MONTAGNER, 2017).

No capitalismo contemporâneo as alterações no mundo do trabalho e na produção vêm sendo implementadas em função do esgotamento dos padrões de acumulação anteriores e à necessidade de modificações para que fossem mantidas a lucratividade, a extração de mais-valia e a busca por acumulação incessante do capital (MÉSZÁROS, 2015).

A combinação no capitalismo, da acumulação flexível e do padrão Toyotista de produção, em conjunto com a crise estrutural capitalista, acarretou o surgimento de novos setores de produção, formas de fornecimento de serviços financeiros e mercados, com isso, houve um aumento significativo de empregos no "setor de serviços" (GENTILLI, 2015), como é o caso dos motofretistas. Esses, por sua vez, acabam por cumprir o papel de concatenar o espaço e tempo de efetivação do pro- 
cesso de produção, circulação, troca e consumo de mercadorias, contribuindo com a aceleração generalizada do fluxo do excedente de valor. Dessa forma, a acumulação flexível também envolve um movimento denominado por Harvey (2020) de "compressão do espaço-tempo", que se refere ao aumento da velocidade associado ao desenvolvimento dos meios de transporte, comunicação, fluxo de informações e racionalizações nas técnicas de distribuição, possibilitadoras da circulação de mercadorias em tempo e custo menores, de forma global.

Alves (2005) assinala que o regime de acumulação flexível busca satisfazer as exigências do capitalismo mundial, sendo adequado às novas condições de concorrência e de valorização do capital e ao novo patamar da luta de classes no modo de produção capitalista. Inerente à acumulação flexível, a reestruturação produtiva se apresenta como saída do capital ante a crise, e nas relações de produção se mostra eficaz para escapar da pressão dos sindicatos, para liberar os custos trabalhistas e ampliar ainda mais a autonomia nas práticas de demissão. Essa tendência leva a uma instabilidade no emprego, e serve para explicar as relações entre trabalho e pobreza, para além do que os indicadores de renda podem revelar no âmbito da questão social.

Ante ao exposto, a lógica da acumulação flexível e a reestruturação produtiva do capital se apoiam na dilapidação da força de trabalho, principalmente no setor de serviços, uma vez que diante de uma vasta reserva de mão de obra e na ausência de uma sólida organização sindical e política da classe trabalhadora, facilita o aumento das taxas de exploração (KOWARICK, 1979; 2016, ANTUNES, 2019), decorrentes do acréscimo da produtividade, com o prolongamento da jornada de trabalho e intensificação do ritmo do trabalho.

Castells (2009; 2018) refere que a denominação “serviços" é enganadora, e se encontra reagrupada em três gêneros de atividades: comércio, administração e "serviços diversos". É sob essa última perspectiva que no Brasil vem ocorrendo um aumento gradativo na quantidade de pessoas que buscam garantir sua subsistência e de seus fa- 
miliares em ocupações pouco ou nada estáveis, no mercado informal de trabalho, dentre os quais estão os trabalhadores motofretistas. O vínculo informal do trabalho é um traço do capitalismo desde o surgimento de modo de produção, o motofretista é um exemplo contemporâneo exatamente cruel. E, ainda, devido à forma de organização do trabalho vigente, que não compromete o Estado nem aqueles a quem presta o serviço, quanto à responsabilidade de assegurar os direitos sociais do trabalho e os meios necessários para sua reprodução, observa-se a falta de assistência e não-recebimento de qualquer benefício em caso de acidente comprometendo ainda mais as condições de vida desses trabalhadores.

Os direitos garantidos pela legislação pertinente aos trabalhadores com registro em carteira de trabalho, são sistematicamente negados aos trabalhadores de motofrete. Em geral, são precárias as condições de trabalho entre trabalhadores de categorias profissionais não-regulamentadas ou pouco organizadas, como é o caso dos motofretistas. A ausência de regulamentação, atrelada à grande oferta de mão de obra contribui para a manutenção de péssimas condições de trabalho a que são submetidos; situações essas que os expõem ao desgaste no trabalho e elevado risco de se envolverem em acidentes de trânsito (SANTANA; ANDRADE; CARDIM, 2015).

A rápida e não planejada urbanização, aliada à ampliação dos prazos e facilidade de créditos, por incentivo do Estado favoreceu significativamente o crescimento da frota de motocicletas no Brasil. Acrescenta-se a isso as dificuldades de mobilidade urbana existentes nas grandes cidades brasileiras, a realidade do trabalho no capitalismo contemporâneo, as condições a que estão submetidos no cumprimento de suas atividades de trabalho e a vulnerabilidade da atividade pela exposição a riscos no transito (SANTANA; ANDRADE; CARDIM, 2015; RODRICUES; ARMOND; GORIOS et al., 2014). Tudo isso se se converte em ingredientes nas condições de trabalho e vida dos motofretistas e revela-se como mais uma expressão atual da questão so- 
cial contemporânea, decorrente do reordenamento do capital em seu processo de expansão e seu sistema exploratório dominante.

\section{Considerações finais}

O modo de produção capitalista define como as sociedades constituem-se, logo, rege todos os aspectos da vida humana. Em suas fases de desenvolvimento histórico, essa forma de organização societal, embora mantenha as características gerais que estruturaram o capitalismo, ocorreram mudanças, essencialmente nas formas de organização do processo de trabalho. Notadamente, na década de 1970, a busca por alternativas à crise do capital exigiu a implantação de um novo regime de acumulação, alicerçado na flexibilidade dos processos de trabalho, dos produtos e padrões de consumo, que fez emergir novos setores de produção e mercados, novas maneiras de fornecimento de serviços, com redução de tempo, espaço e custo de circulação, além da intensificação das taxas de inovação comercial, tecnológica e organizacional. (HARVEY, 2020).

Essas transformações, que culminaram na reestruturação produtiva do capital, vieram acompanhadas da flexibilização da regulação social do trabalho, expressas: em formas flexíveis de contratação da força de trabalho, tais como terceirização, remuneração variável e modulação da jornada diária de trabalho; na desregulamentação de direitos e, consequentemente diminuição da proteção social ao trabalhador; na regulação privada do trabalho, ampliando o espaço para o empregador definir; no enfraquecimento do poder sindical; na reconfiguração da classe trabalhadora, cada vez mais fragmentada, heterogênea, localizada setor de serviços que tem maior dificuldade de organização coletiva, como é o caso dos trabalhadores motofretistas.

Os motofretistas, enquanto pertencentes à noção ampliada da classe trabalhadora, são prestadores de serviços do setor de transportes, nos distintos espaços de circulação das cidades, logo, esse é seu ambiente de trabalho. Assim, a mobilidade no espaço público 
das cidades é elemento do processo de produção do espaço na sociedade capitalista e de reprodução da vida cotidiana, à medida em que são lócus de produção, circulação, troca e consumo das mercadorias por sujeitos diversos, é onde se dão as relações sociais, incluso as condições de trabalho dos motofretistas.

Destaca-se aqui, a periculosidade inerente a esse tipo de transporte utilizado como meio de trabalho dos motofretistas, visto que ficam totalmente expostos ao ambiente. Portanto, o risco, a gravidade nos acidentes e mortes aos quais esses trabalhadores estão submetidos, retratados nos dados obtidos junto ao Departamento de Informática do Sistema Único de Saúde, precisam ser analisados e discutidos em um quadro mais amplo da realidade concreta e da organização das cidades brasileiras, no contexto da acumulação flexível da sociedade capitalista atual.

Ademais, neste cenário, deve-se levar em conta a demanda de “compressão do espaço-tempo", imposta pela reprodução do capital aos trabalhadores motofretistas, para viabilizar a aceleração do processo de produção, circulação, troca e consumo de mercadorias, com menor custo e maior agilidade A necessidade de realizarem o maior número possível de entregas de mercadorias em um curto intervalo de tempo em meio a um trânsito saturado de veículos, com os quais dividem e disputam as ruas da cidade, em condições insalubres e estressantes, sujeitam os trabalhadores motofretistas a uma condição de vida mais precária e explorada de trabalho, potencializando a ocorrência de acidentes fatais. Nessa ótica, conclui-se que os trabalhadores motofretistas são essenciais no processo de reprodução do capital. A venda de sua força de trabalho, enquanto mercadoria, é consumida de modo produtivo, por meio da compra de mais força de trabalho. E, a utilidade de seu trabalho, que contribui com a acelerada circulação e troca de mercadorias, permite, de forma constante e mais rápida, a realização mais-valia. 


\section{Referências}

ABREU, Ângela Maria Mendes et al. Impacto da lei seca na mortalidade por acidentes de trânsito. Revista Enfermagem, v. 20, n¹, 2012, p.21-26.

ALMEIDA, G. C. M.; MEDEIROS, F. C. D.; PINTO, L. O. et al. Prevalência e fatores associados a acidentes de trânsito com mototaxistas. Revista Brasileira de Enfermagem, Natal, v. 69, n. 2, p. 382-8, mar./abr., 2016. https://www. scielo.br/pdf/reben/v69n2/0034-7167-reben-69-02-0382.pdf

ALVES, G. Trabalho, corpo e subjetividade: Toyotismo e formas de precariedade no capitalismo global. Trabalho, Educação \& Saúde, Rio de Janeiro, v. 3, n. 2, p. 409-28, 2005. https://www.scielo.br/pdf/tes/v3n2/09.pdf

ANTUNES, Ricardo. O privilégio da servidão. São Paulo, 2019.

ANTUNES, Ricardo. O privilégio da servidão: o novo proletariado de serviço na era digital. Boitempo editorial, 2018.

BARROS, F. H.V.; SILVA, L. O.; ROSENO, M. A. S. G. et al. Prevalência dos Acidentes de Motocicleta Envolvendo os Adolescentes de Quixadá. Id on Line Revista Multidisciplinar e de Psicologia, Ceará, v. 12, n. 42, Supl. 1, p. 511-524, 2018. https://idonline.emnuvens.com.br/id/article/view/1454/2079

BOTELHO, L. J.; GONZAGA, H. N. Mortalidade por acidentes motociclísticos: estudo comparativo entre Santa Catarina e Brasil. Boletim do Curso de Medicina UFSC, Santa Catarina, v. 8, n. 3, p. 8-14, 2017. file:///C:/Users/PC/Downloads/2427-7894-1-PB.pdf

BRASIL. Ministério da Saúde. A declaração de óbito. Documento necessário e importante. 3.ed. Ministério da Saúde: Brasília, 2011. Disponível em:

https://portalarquivos2.saude.gov.br/images/pdf/2015/agosto/14/Declaracao-de-Obito-WEB.pdf

CARVALHO, C. H. R. (2016). Mobilidade urbana: Avanços, desafios e perspectivas. In: O Estatuto da Cidade e a Habitat III: um balanço de quinze anos da política urbana no Brasil e a Nova Agenda Urbana. Brasília: IPEA, 2016. Disponivel em: http://repositorio.ipea.gov.br/bitstream/11058/9186/1/Mobilidade\%20urbana.pdf

CASTELLS, M. A questão urbana. 4.ed. Coleção Pensamento Crítico - Vol. 48. São Paulo: Paz e Terra, 2009.

CASTELLS, M. Ruptura: a crise da democracia liberal. Rio de Janeiro: Zahar, 2018. 
CORGOZINHO, M. M.; MONTAGNER, M. A. Vulnerabilidade humana no contexto do trânsito motociclístico. Saúde e Sociedade, São Paulo, v. 26, n. 2, p. 545-55, 2017. https://www.scielo.br/pdf/sausoc/v26n2/1984-0470-sausoc-26-02-00545.pdf

CRUZ, M. M. L. Série Acidentes de trânsito com motocicletas: uma visão do cenário e das propostas de solução no Brasil e no mundo. São Paulo: Companhia de Engenharia de Tráfego, 2019. http://www.cetsp.com.br/media/936406/bt-61.pdf

CUNHA, A. M. Cidade e questão social no capitalismo: em cena, Fortaleza, a Miami do nordeste. Revista Políticas Públicas, São Luís, v. 12, n. 2, p. 65-73, jul./dez., 2008. https://www.redalyc.org/pdf/3211/321127274007.pdf

DA CUNHA C.J.; FURTADO, D. B. S.; DIAS, R. de et al. Mobilidade urbana e segregação: uma análise a partir das calçadas do Distrito Jardim Ângela/ São Paulo - SP - Brasil. Latin American Journal of Business Management, Taubaté, v. 9, n. 2, p. 114-127, jul-dez/2018. https://portal.aprendiz.uol.com. br/2018/09/18/mobilidade-nao-e-sinonimo-de transporte/?gclid=CjwKCAiAr6ABhAfEiwADO4sfUuTzXPymR5DjYNkvsaujRYmGEdRe7yQoCuC3hnmEOh3xejEeaDr-BoCxOcQAvD_BwE

DATASUS. Ministério da Saúde. Portal da Saúde. 2019. Disponível em: https:// datasus.saude.gov.br/acesso-a-informacao/

FRACA, A. C. G. A política nacional de mobilidade urbana e a profissão de motofretista. 2016. 114 f. Dissertação (Mestrado em Políticas Públicas e Desenvolvimento Local) - Programa de Pós-Graduação em Políticas Públicas e Desenvolvimento Local, Escola Superior de Ciências da Santa Casa de Misericórdia de Vitória - EMESCAM, Vitória, 2016.

FRANKLIN, R.; BORGES, R.; SÁNCHEZ, C.; MONTIBELER, E. World Labour Values Data Panel. Disponivel em: https://panel.worldlabourvalues.org. 2021.

FRANKLIN, R.; BORGES, R.; SÁNCHEZ, C.; MONTIBELER, E. Skilled labour and the reduction problem: questioning the exploitation rate equalization hypoyhesis. World Review of Political Economy (no prelo), 2021.

GENTILLI, R. M. L. Transformações societárias recentes e as raízes da violência atual. In. GENTILLI, R. M. L.; COELHO, M. C. R. (Orgs.). Investigações sobre violência e sociabilidade: desafios transdisciplinares. São Paulo: Veras, 2015, p. $18-40$.

GOLIAS, A. R. C.; CAETANO, R. Acidentes entre motocicletas: análise dos ca- 
sos ocorridos no estado do Paraná entre julho de 2010 e junho de 2011. Ciências \& Saúde Coletiva, Rio de Janeiro, v. 18, n. 5, p. 1235-46, 2013. https:// www.scielosp.org/article/csc/2013.v18n5/1235-1246/pt/

HARVEY, D. A produção capitalista do espaço. São Paulo: Annablume, 1989.

IAMAMOTO, M. V. O Brasil das desigualdades: “questão social", trabalho e relações sociais. SER Social, Brasília, v. 15, n. 3, p. 261-384, jul./dez., 2013. http:// wWw.cressrn.org.br/files/arquivos/FaPa1Oy8kQ65voJ4T345.pdf

IAMAMOTO, M. V. Mundialização do capital, "questão social” e serviço Social no Brasil. Revista Em Pauta, Rio de janeiro, n. 21, p. 117-139, 2008.

KOWARICK, L. A espoliação urbana. Rio de Janeiro: Paz e Terra, 1979.

KOWARICK, L. A pluralidade urbana em São Paulo. São Paulo: Editora 34, 2016.

LIMA, M. V. P.; PACHÚ, C. O. Gasto público com acidentados de moto no ano de 2013 em hospital de referência de Campinha Grande-PB. 2016.

LIMA, M. V. P.; PACHÚ, C. O. Gastos públicos com acidentados de moto no ano de 2013 em hospital de referência em Campina Grande-PB. 2016.

MALTA, D. C.; ANDRADE, S. S. C. de A.; GOMES, N. et al. Lesões no trânsito e uso de equipamento de proteção na população brasileira, segundo estudo de base populacional. Ciência \& Saúde Coletiva, Rio de Janeiro, v. 21, n. 2, p. 399409, 2016. https://www.scielosp.org/article/csc/2016.v21n2/399-410/pt/

MANCINI, E. L., A. R. O percurso das políticas urbana e habitacional brasileiras e seus "novos" rumos. Revista de Políticas Públicas, São Luís, v. 12, n. 2, p. 35-43, jul./dez. 2008. http://www.periodicoseletronicos.ufma.br/index. php/rppublica/article/view/3849/1985

MARTINS, Evandro Tostes; BOING, Antonio Fernando; PERES, Marco Aurélio. Mortalidade por acidentes de motocicleta no Brasil: análise de tendência temporal, 1996-2006. Revista de Saúde Pública, São Paulo, v. 47, n. 5, p. 931 41, 2013. https://www.scielosp.org/article/rsp/2013.v47n5/931-941/

MÉSZÁROS, Í. A montanha que devemos conquistar: reflexões acerca do Estado. São Paulo: Boitempo Editorial, 2015.

MESQUITA FILHO, M. Acidentes de trânsito: as consequências visíveis e invisíveis à saúde da população. Revista Espaço Acadêmico, São Paulo, Ano XI, n. 128, p. 148-57, jan., 2012. http://periodicos.uem.br/ojs/index.php/EspacoAcademico/article/view/13630 
MORAIS NETO, O. L.; MONTENEGRO, M. M. S.; MONTEIRO, R. A.et al. Mortalidade por acidentes de transporte terrestre no Brasil na última década: tendência e aglomerados de risco. Ciências \& Saúde Coletiva, Rio de Janeiro, v. 17, n. 9, p. 2223-36, 2012. https://www.scielo.br/pdf/csc/v17n9/aO2v17n9.pdf MORAIS NETO, O. L.; MALTA, D. C.; MASCARENHAS, M. D. M. et al. Fatores de risco para acidentes de transporte terrestre entre adolescentes no Brasil: Pesquisa Nacional de Saúde do Escolar (PeNSE). Ciências \& Saúde Coletiva, Rio de Janeiro, v. 15, Supl. 2, p. 3043-3052, 2010. https://www.scielo.br/pdf/ $\mathrm{csc} / \mathrm{v} 15 \mathrm{~s} 2 / \mathrm{aO} 9 \mathrm{v} 15 \mathrm{~s} 2 . \mathrm{pdf}$

NASCIMENTO, D. M. As políticas habitacionais e as ocupações urbanas: dissenso na cidade. Cadernos Metrópole, São Paulo, v. 18, n. 35, p. 145-164, abr. 2016. https://www.scielo.br/pdf/cm/v18n35/2236-9996-cm-18-35-0145.pdf

NORONHA, C. K. C.; MORAIS, E. R. Ocorrência de óbitos por acidentes de motocicletas em Teresina, Estado do Piauí, Brasil. Revista Panamericana de Saúde, Teresina, v. 2, n. 4, p. 11-16, 2011. http://scielo.iec.gov.br/scielo.php?pi$\mathrm{d}=$ S217662232011000400002\&script=sci_arttext\&tlng=en

PEREIRA, M. F. V. A inserção subordinada do Brasil na divisão internacional do trabalho: consequências territoriais e perspectivas em tempos de globalização. Sociedade \& Natureza, Uberlândia, v. 22, n. 2, p. 347-355, 2010.

PERO, V.; STEFANELLI, V. A questão da mobilidade urbana nas metrópoles brasileiras. Revista de Economia Contemporânea, Rio de Janeiro, v. 19, n. 3, p. 366-402, 2015.https://www.scielo.br/pdf/rec/v19n3/1415-9848rec-19-03-00366.pdf

PONTES, L. R. S.; MACIEL, J. S. C. O estresse como fator gerador de acidentes e consequente aumento da falta de mobilidade urbana. VI SINCEP. Simpósio Internacional de Gestão de Projetos, Inovação e Sustentabilidade. V ELBE Encontro Luso-Brasileiro de Estratégia. 2017. https://singep.org.br/6singep/ resultado/406.pdf

RODRICUES, C. L.; ARMOND, J. E.; COLOMBO-SOUZA, P. et al. Acidentes que envolvem motociclistas no município de São Paulo: caracterização e tendências. Revista Brasileira de Ortopedia, São Paulo, v. 49, n. 6, p. 602-606, 2014. https:// www.scielo.br/pdf/rbort/v49n6/pt_0102-3616-rbort-49-06-0602.pdf

RUBIM, B.; LEITÃO, S. O Plano de Mobilidade Urbana e o futuro das cidades. Estudos Avançados, São Paulo, v. 27, n. 79, p. 55-66, 2013. https://www.scielo.br/pdf/ea/v27n79/v27n79a05.pdf 
SANTANA, J. S.; ANDRADE, M. G.; CARDIM, A. Motoboys: condições de trabalho e o impacto dos acidentes no desempenho das suas funções. 2015. http://www7.bahiana.edu.br/jspui/bitstream/bahiana/571/2/Capa\%20 e\%20contra\%20-\%20capa.pdf

SCHOELLER, S. D.; BONETTI, A.; SILVA, G. A et al. Características das vítimas de acidentes motociclísticos atendidas em um centro de reabilitação de referência estadual do sul do Brasil. Acta Fisioterapia, Santa Catarina, v. 18, n. 3 , p. 141-45, 2011. http://www.revistas.usp.br/actafisiatrica/article/view/103641 SILVA, R. A. Caracterização dos acidentes de trânsito e das vítimas atendidas pelo SAMU. Revista de Enfermagem, Pernambuco, v. 5, n. 10, p. 2462-69, 2011. https://pesquisa.bvsalud.org/portal/resource/pt/biblio-1033080

TRINDADE, T. A. Direitos e cidadania: reflexões sobre o direito à cidade. Lua Nova. São Paulo, n. 87, p. 139-165, 2012. https://www.scielo.br/pdf/In/ n87/07.pdf

VASCONCELLOS, E. A. Risco no trânsito, omissão e calamidade: impactos do incentivo à motocicleta no Brasil. São Paulo: Annablume, 2016.

\section{Notas}

1 Mestre em Políticas Públicas e Desenvolvimento Local da Escola Superior de Ciências da Saúde da Santa Casa de Misericórdia de Vitória. Médico, Diretor Médico de Operações do MedSênior. Brasil, ericgaigher@gmail.com

2 Doutora em Serviço Social. Professora do programa de Mestrado em Políticas Públicas e Desenvolvimento Local da Escola Superior de Ciências da Saúde da Santa Casa de Misericórdia de Vitória. Brasil. ID Orcid https://orcid.org/00000002-3143-9708. Gissele.Carraro@emescam.br

3 Doutora em Educação. Professora do programa de Mestrado em Políticas Públicas e Desenvolvimento Local da Escola Superior de Ciências da Saúde da Santa Casa de Misericórdia de Vitória. Brasil. ID Orcid - https://orcid.org/0000-00026248-605. Silvia.Trugilho@emescam.br

4 Doutora em Enfermagem. Professora do Programa de Mestrado em Políticas Públicas e Desenvolvimento Local da Escola Superior de Ciências da Saúde da Santa Casa de Misericórdia de Vitória. Brasil. ORCID: https://orcid.org/0000-00024556-5107. Maria.coelho@emescam.br 
5 Periferias são aglomerados distantes dos centros, clandestinos ou não, carentes de infraestrutura, onde passa a residir crescente quantidade de mão-de-obra necessária para fazer girar a máquina econômica (KOWARICK, 1979).

6 Esses dados podem ser consultados em painel elaborado por FRANKLIN, R.; BORGES, R,; SÁNCHEZ, C.; MONTIBELER, E. World Labour Values Data Panel. Disponivel em: https://panel.worldlabourvalues.org. 2021. 